\title{
Cost of children's healthy versus unhealthy snacks do not differ at convenience stores
}

Research Brief

\section{Authors:}

Robin S. DeWeese, PhD, RDN (corresponding author)

Punam Ohri-Vachaspati, PhD, RD

\section{Acknowledgements}

This research was funded by a National Institute of Food and Agriculture predoctoral dissertation fellowship (20146701122279) and by a grant from the National Institute of Child Health and Human Development (1R01HD071583-01A1). 


\begin{abstract}
Objective: This study compared the prices of unhealthy (chips) and healthy (ready-to-eat fruit) snacks that students are likely to purchase from corner stores.

Methods: Snacks were purchased from 325 New Jersey corner stores; chip prices were compared to fruit prices overall and by store sales volume and block group characteristics.

Results: Prices did not differ significantly between chips and fruit in the overall sample in which both items were available ( $\mathrm{n}=104$ ) (chips: $\$ 0.46 \pm \$ 0.15$; fruit: $\$ 0.49 \pm \$ 0.19 ; \mathrm{p}=0.48$ ), or by store or block group characteristics. Neither mean fruit prices nor mean chip prices differed by store sales volume or by neighborhood characteristics.

Conclusions and Implications: Promoting ready-to-eat fruits in corner stores to children as a price-neutral alternative to calorically dense snacks can be a viable strategy to improve the nutritional quality of snacks commonly purchased at corner stores. (136 words)
\end{abstract}

Keywords: diet, food, and nutrition 


\section{Introduction}

2 Small retail food stores tend to concentrate near schools, ${ }^{1}$ providing students ready access to

3 snacks on the way to and from school each day. ${ }^{2}$ While some corner stores may stock healthier

4 options, these tend to be more expensive compared to their less nutritious counterparts. ${ }^{3}$ Food

5 prices contribute to students' eating behaviors, as adolescents, most of whom have a limited

6 amount of spending money, consider price, among other factors, when choosing which foods to

7 purchase and eat. ${ }^{4,5}$ The purpose of this study was to compare corner store prices of an energy-

8 dense, nutrient-poor snack students are likely to purchase (chips), ${ }^{2}$ to prices for healthy, ready-to-

9 eat snacks (fruit). We hypothesized that fruit would cost more than chips.

\section{Methods}

12 Store audits were conducted in 2014 for a cross-sectional study that developed and validated a

13 reduced audit instrument. ${ }^{6}$ Details of that study are provided elsewhere. ${ }^{6}$ Briefly, it was part of

14 the New Jersey Child Health Study, and the sample of 325 New Jersey corner stores was

15 powered for that project. The sampling frame consisted of small food stores listed in 2013

16 commercially available business lists (InfoUSA and Nielsen) for the metro areas of Camden,

17 Newark, New Brunswick, and Trenton, NJ. Because the only data collected from participants

18 related to store inventories, the study was granted an exempt status by the Arizona State

19 University IRB.

21 Addresses of stores were geocoded using ArcGIS to obtain Census block group codes. Stores

22 were matched with their corresponding block group's characteristics including proportion of

23 residents at least 25 years old with at least a high school education, median income, proportion of 
24 households earning less than $150 \%$ of the federal poverty level (FPL), race/ethnicity, proportion

25 of female-headed households, proportion of households with residents under 18 years old, and

26 proportion of residents at least 16 years old who are unemployed. Block group characteristics

27 were obtained from the American Community Survey Summary File Retrieval Tool. ${ }^{7}$ Store sales

28 volume was obtained from business files.

30 Data collectors completed the 325 audits in June, July, August, and December. After completing

31 each audit, data collectors purchased the smallest bag of chips sold in the store and a ready-to-eat

32 fresh fruit if available. In most stores the smallest bag of chips was one ounce; in some cases,

33 however, only larger sizes were available. Fresh fruits were considered 'ready-to-eat' if they did

34 not require peeling (e.g., apple), if they could be peeled without a utensil (e.g., orange), or if they

35 were cut up and in a single-serve container (e.g., cup of watermelon). Purchased fruits that

36 qualified for this analysis included bananas, apples, oranges, pears, plums, peaches, nectarines,

37 strawberries, and a mixed fruit cup. Data collectors recorded the name, size, and price of each

38 purchase they made. The present analysis includes only stores from which a one-ounce bag of

39 chips and a ready-to-eat fruit were purchased.

41 Means and standard deviations were used to summarize purchase prices, store sales volume, and

42 block group characteristics. Paired t-tests were conducted to compare fruit and chip prices

43 overall, by store sales volume and block group characteristics, and by time of year (3 summer

44 months vs December). A one-way between-groups analysis of variance was conducted to

45 analyze differences in chip and fruit price differences and to analyze fruit and chip prices 
46 separately according to store sales volume and block group characteristics. Chip and fruit prices

47 were not normally distributed, and were log-transformed for analysis.

\section{Results}

50 Characteristics of the stores included in the sample and of the block groups where these stores

51 were located are presented in Table 1 . On average $45 \% \pm 19 \%$ of households in block groups

52 where sampled stores were located earned less than $150 \%$ of the FPL. Block groups were

53 predominately non-Hispanic black and Hispanic, with an average unemployment rate of

$5413 \% \pm 6 \%$. Further, $70 \% \pm 16 \%$ of residents across all block groups had at least a high school

55 education or general education diploma (GED). The average sales volume of all stores was less

56 than $\$ 1$ million. One-ounce bags of chips were purchased from $56 \%$ of stores, $54 \%$ of stores had

57 ready-to-eat fruit, and $32 \%$ of stores had both. The mean price of all chips $(\mathrm{n}=181)$ was

$58 \$ 0.47 \pm \$ 0.16$ compared to $\$ 0.52 \pm \$ 0.20$ for all ready-to-eat fruit $(n=177)$ (Table 2$)$. Prices did not

59 differ between summer months and December. When comparing the mean price of chips to that

60 of fruit in only stores where both items were available $(n=104)$, chips were $\$ 0.46 \pm \$ 0.15$ and fruit

61 was $\$ 0.49 \pm \$ 0.19$ (Table 2, Figure). This difference was not significant. As shown in the figure,

62 while mean fruit prices tended to be a few cents higher than mean chip prices were across all

63 subgroups, none of the differences were statistically significant, nor were any of the differences

64 between the mean cost of fruit and chips significant. Neither mean fruit prices nor mean chip

65 prices differed by store sales volume or by neighborhood characteristics.

66

67 Discussion 
68 This study focused on two food items students might be inclined to purchase as snacks from

69 small stores often located near schools. ${ }^{1,2}$ In the overall sample as well as in all subsamples, a

70 student would spend approximately the same amount on either a ready-to-eat fruit or a one-ounce

71 bag of chips.

73 This is good news for communities instituting healthy corner store programs to increase the

74 availability of healthy foods in their neighborhoods. Small-store owners might be reluctant to

75 lower prices on fruits and vegetables to increase sales, but in this sample, price reductions seem

76 unnecessary. Promoting ready-to-eat fruits to children may result in students choosing fruit over

77 an unhealthy snack, and would be more viable for store owners than would lowering prices.

78 Borradaile et al. found that, on average, children purchased approximately 360 calories per trip

79 to a corner store on the way to/from school, and that those purchases were primarily composed

80 of chips, candy, and sugary beverages. ${ }^{2}$ A student who visited a corner store just three times per

81 week and exchanged an energy dense, nutrient poor snack for a fruit or vegetable snack could

82 reduce his/her calorie consumption by approximately 300 calories per week, while also adding

83 vitamins, minerals, and fiber to his/her diet.

85 Healthy corner store initiatives targeting children for interventions to encourage them to choose

86 healthy snacks over unhealthy ones have not always proven effective. ${ }^{8,9}$ A change in societal

87 norms concerning what constitutes a "snack," a process that could require years of exposure,

88 may be necessary for a change in children's snacking preferences. 
90 Healthier foods and food patterns have been found to be more expensive overall compared to

91 their less nutritious counterparts. ${ }^{10}$ Almost half the stores in this sample had no ready-to-eat

92 fruits, and an alternative fruit or vegetable, such as a mango, was purchased. When these fruits

93 and vegetables were included in analyses, healthy snacks cost significantly more compared to

94 chips. The increased price of these types of fruits and vegetables is relatively inconsequential

95 when considering their impact on children's purchasing behaviors, as children are unlikely to

96 select as a snack a fruit or vegetable requiring any sort of preparation before it can be consumed.

97 The more important issue is the lack of any child-friendly ready-to-eat fruits or vegetables in

$9846 \%$ of stores sampled. Making healthy snacks that children can immediately eat available in

99 corner stores is another important consideration in addition to price and promotion

100 considerations.

101

\section{Implications for Research and Practice}

103 Promoting ready-to-eat fruits in corner stores to children as a price-neutral alternative to

104 calorically dense snacks can be a viable strategy to improve the nutritional quality of snacks

105 commonly purchased at corner stores. These promotions will require considerable ongoing effort

106 to be effective as they are competing both with societal norms of snacking, and with established

107 and constantly evolving promotional efforts by large corporations.

108

109

110

111

112 


\section{References}

114 1. Sturm R. Disparities in the food environment surrounding US middle and high schools. Public

115 Health. 2008;122(7):681-690.

116 2. Borradaile KE, Sherman S, Vander Veur SS, et al. Snacking in children: The role of urban

117 corner stores. Pediatrics. 2009;124(5):1293-1298.

118 3. Cavanaugh E, Mallya G, Brensinger C, Tierney A, Glanz K. Nutrition environments in corner

119 stores in Philadelphia. Prev Med. 2013;56(2):149-151.

120 4. Watts AW, Lovato CY, Barr SI, Hanning RM, Mâsse LC. A qualitative study exploring how

121 school and community environments shape the food choices of adolescents with

122 overweight/obesity. Appetite. 2015;95:360-367.

123 5. French SA. Pricing effects on food choices. J Nutr. 2003;133(3):841S-843S.

124 6. DeWeese RS, Todd M, Karpyn A, et al. Short-form audit instrument for assessing corner store 125 healthfulness. Am J Health Promot. 2016;In press.

126 7. US Census Bureau. American Community Survey (ACS) website.

127 http://www.census.gov/programs-surveys/acs/. Updated 2015. Accessed March 1, 2016.

128 8. Hoffman JA, Morris V, Cook J. The Boston middle school-corner store initiative:

129 Development, implementation, and initial evaluation of a program designed to improve

130 adolescents' beverage-purchasing behaviors. Psychol Sch. 2009;46(8):756-766. 
131 9. Lent MR, Vander Veur SS, McCoy TA, et al. A randomized controlled study of a healthy

132 corner store initiative on the purchases of urban, low-income youth. Obesity. 2014;22(12):2494-

1332500.

134 10. Rao M, Afshin A, Singh G, Mozaffarian D. Do healthier foods and diet patterns cost more

135 than less healthy options? A systematic review and meta-analysis. BMJ Open.

$136 \quad 2013 ; 3(12): \mathrm{e} 004277-2013-004277$.

\section{Figure caption}

139 Figure. Comparison of mean chip prices overall; by store sales volume; and by block group

140 majority race, education level proportion, proportion earning < $150 \%$ of the Federal Poverty

141 Level, and unemployment proportion. Only stores that have both chips and ready-to-eat fruit.

142 Paired t-tests used to compare fruit prices to chip prices in each category. None of the

143 comparisons were significant. Data transformed for analysis. 
Table 1. Mean proportions of education level, employment status, race/ethnicity, household income, and head of household status in block groups in which study stores were located; mean employee count, sales volume, and square footage of study stores

\begin{tabular}{lc}
\hline Block group characteristics $(\mathbf{n = 1 0 4})$ & Mean \pm SD (\%) \\
\hline At least high school/general education degree (GED) education & $70 \pm 16$ \\
Unemployed & $13 \pm 6$ \\
White, non-Hispanic & $5 \pm 12$ \\
Black, non-Hispanic & $54 \pm 34$ \\
Hispanic/Latino & $37 \pm 31$ \\
Household income <150\% of federal poverty level & $45 \pm 19$ \\
Female head of household w/children & $28 \pm 12$ \\
\hline Store characteristics $(\mathbf{n}=\mathbf{1 0 0})$ & Mean \pm SD \\
\hline Number of employees & $2.8 \pm 1.2$ \\
Sales volume (\$) & $739,177 \pm 268,067$ \\
Floor area (square feet) & $1272 \pm 129$ \\
\hline
\end{tabular}


Table 2. Price means, medians, and inter-quartile ranges of one-ounce chips and ready-to-eat fruit purchased from study stores

\section{Mean \pm SD (\$) Median (\$) (IQR)}

All

Chips $(\mathrm{n}=181)$

$.47 \pm .16 \quad .50(0.35-0.50)$

Fruit $(\mathrm{n}=177)$

$.52 \pm .20 \quad .50(0.40-0.50)$

Stores with both chips \& fruit $(\mathrm{n}=104)$

Chips

$.46 \pm .15 \quad .50(0.35-0.50)$

Fruit

$.49 \pm .19$

$.50(0.35-0.50)$ 

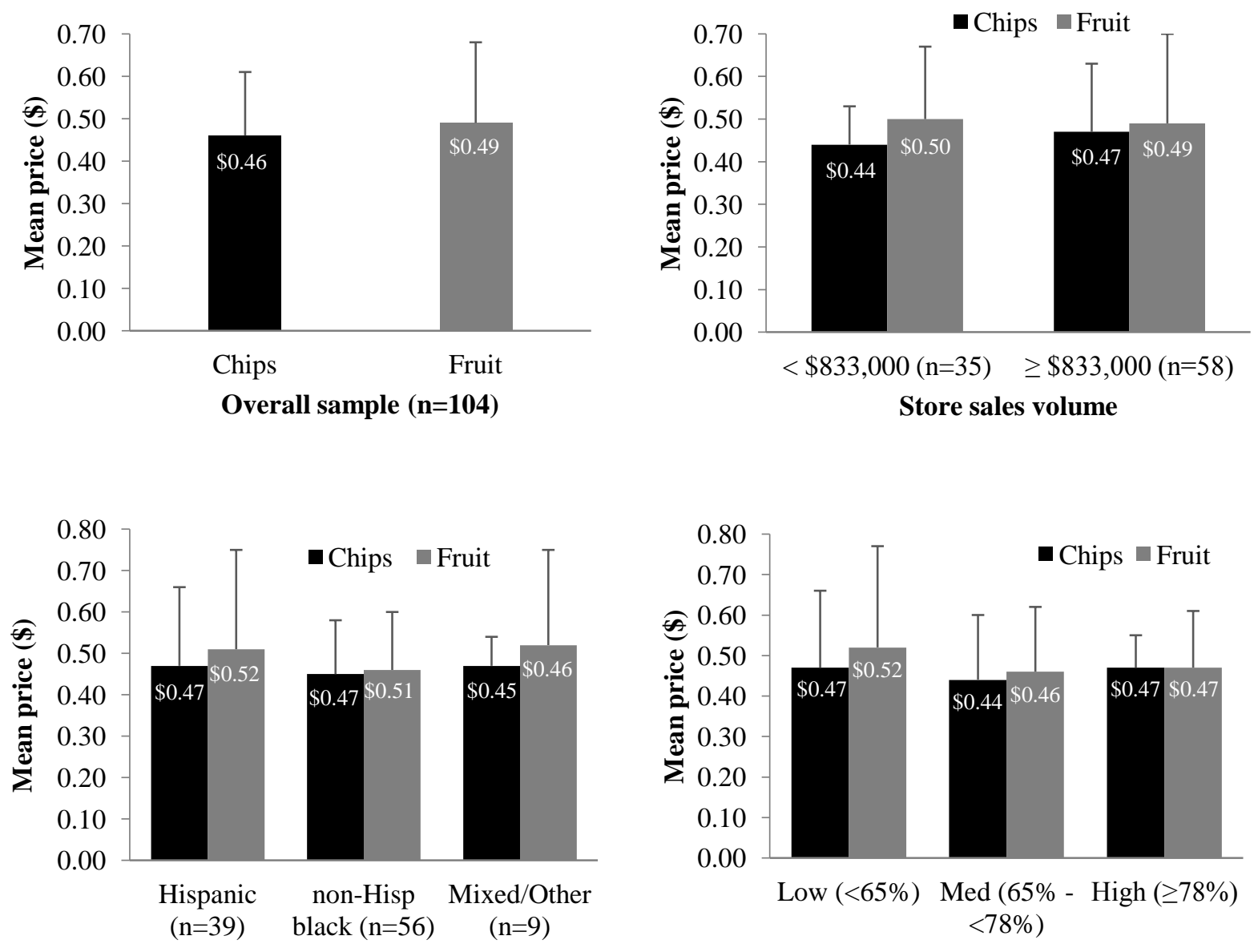

Majority race of block group
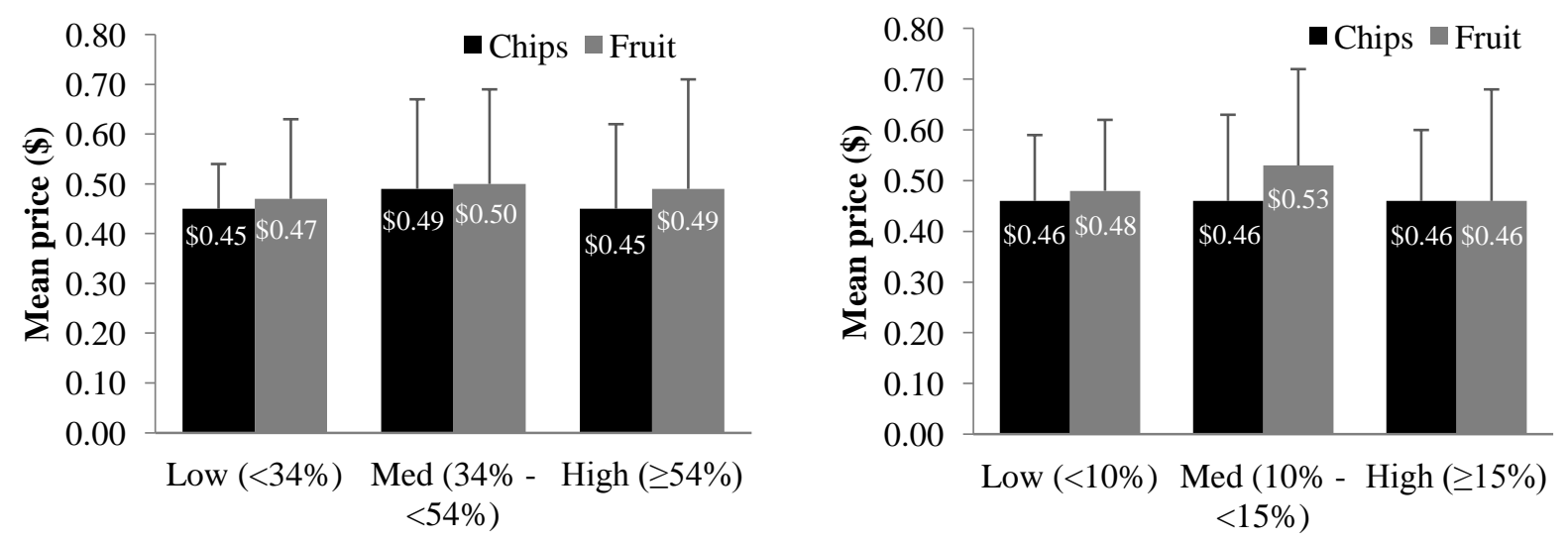

Block group proportion earning $<150 \%$ of Federal Poverty Level

Block group proportion unemployed 